Article

\title{
Asymmetrical Complexity in Languages Due to L2 Effects: Unserdeutsch and Beyond
}

\author{
Siegwalt Lindenfelser $(\mathbb{D}$ \\ Department of German Linguistics instead of Chair for German Linguistics, University of Bamberg, \\ Hornthalstraße 2, 96045 Bamberg, Germany; siegwalt.lindenfelser@uni-bamberg.de
}

Received: 22 September 2020; Accepted: 3 November 2020; Published: 11 November 2020

\begin{abstract}
This study examines asymmetries between so-called inherent and contextual categories in relation to the morphological complexity of the nominal and verbal inflectional domain of languages. The observations are traced back to the influence of adult $\mathrm{L} 2$ learning in scenarios of intense language contact. A method for a simple comparison of the amount of inherent versus contextual categories is proposed and applied to the German-based creole language Unserdeutsch (Rabaul Creole German) in comparison to its lexifier language. The same procedure will be applied to two further language pairs. The grammatical systems of Unserdeutsch and other contact languages display a noticeable asymmetry regarding their structural complexity. Analysing different kinds of evidence, the explanatory key factor seems to be the role of (adult) L2 acquisition in the history of a language, whereby languages with periods of widespread L2 acquisition tend to lose contextual features. This impression is reinforced by general tendencies in pidgin and creole languages. Beyond that, there seems to be a tendency for inherent categories to be more strongly associated with the verb, while contextual categories seem to be more strongly associated with the noun. This leads to an asymmetry in categorical complexity between the noun phrase and the verb phrase in languages that experienced periods of intense L2 learning.
\end{abstract}

Keywords: inflection; L2 effects; morphological complexity; simplification; second language acquisition; Unserdeutsch

\section{Introduction}

In debates about language complexity, two kinds of grammatical categories have been distinguished: categories that serve essential communicative purposes, and categories that do not add any communicative bonus but only fulfil intralinguistic functions. ${ }^{1}$ The latter have been labelled with contemptuous terms like "ornamental elaboration", "baroque accretion" (McWhorter 2001, p. 132), or even "afunctional historical baggage" (Trudgill 2011a, p. 162). An example would be grammatical gender like in Standard German. Although grammatical gender always has some semantic basis (Dixon 2016, p. 77), larger parts of this semantic basis often evolve over time into an opaque classification that is not transparent anymore for language users. Moreover, it does not add essential communicative value for them (although it can nevertheless be regarded as a "desirable" grammatical category in that it "serve[s] to categorise the world", Dixon 2016, p. 81). Beyond categories in a strict sense, inflectional

1 I wish to thank Alexandra Aikhenvald and two anonymous reviewers for their critical comments and helpful suggestions on an earlier version of this paper and both Lotta Christiansen and Hümeyra Uzunkaya for stylistic advice. Of course, all errors and shortcomings are in my own responsibility. I also wish to thank the participants of the special workshop "Language Contact and the Emergence of Hybrid Grammars" in Cairns in summer 2018 for fruitful discussions on a very early version of the idea of this article. 
classes and the existence of grammatical agreement also belong to this class of features. These features have in common that they are hard to learn, especially for adults (since the features are not motivated), while, however, they do not actually hinder communication when they are used in the wrong way. As Corbett put it with reference to grammatical agreement: "agreement often appears to involve a lot of effort for a questionable payoff" (Corbett 2006, p. 274).

This hitherto fairly vague differentiation has been articulated in a more fine-grained manner before. Kiparsky (1982, p. 99) distinguished strong categories "associated with largely fixed meanings of their own" (like number or tense) from weak categories "which register information that is relatively redundant" (like grammatical case or person/number as verbal categories in non-pro-drop languages). ${ }^{2}$ He already concluded that the weak categories would be "easily subject to morphological erosion" (ibid.) in learning or contact scenarios, while strong categories would tend to remain intact.

Booij $(1993,1995)$ later introduced a similar concept, which will be used here. He differentiates between inherent inflection ( $\hat{=}$ strong categories), which "expresses [ ... ] a certain amount of independent information" (Booij 1993, p. 30), like number on nouns, comparative on adjectives, or tense on verbs, and contextual inflection ( $\hat{=}$ weak categories), which "only reflects certain aspects of the syntactic structure of the sentence" (ibid.), as for example and in particular grammatical case or gender in noun phrases. ${ }^{3}$

In this paper, a simple test is proposed to distinguish between these two types of categories and then to count them for a given language. First and foremost, the distribution of inherent and contextual categories will be examined across the nominal and verbal domain of the creole language Unserdeutsch in comparison to its lexifier language, which is spoken Standard German. Subsequently, the method is also briefly applied to two other language pairs: Tok Pisin and its lexifier language English as well as Afrikaans versus its parent language Dutch. Drawing on studies about simplicity and complexity, especially in creole languages, as well as on (adult) L2 learning in general, the already existing hypothesis of a connection between (adult) L2 learning and simplification is further developed with regard to a possible asymmetry in the grammatical systems of these languages.

After introducing four hypotheses on the possible impact of (adult) L2 learning on both contextual and inherent categories in Chapter 2, information the Unserdeutsch corpus as well as the methods used will be given in Chapter 3. Chapter 4 then contains the main study about Unserdeutsch. In Chapter 5, additional information is given on general complexity-related categorical preferences in pidgin and creole languages. Two more specific language pairs are contrasted in Chapter 6 , followed by a discussion (Chapter 7) as well as conclusions (Chapter 8).

\section{Do Contextual Categories Tend to Erode in SLA Scenarios?}

The hypothesis from the introduction that some categories might be more essential than others leads to a follow-up question: Are some categories more likely to be omitted in scenarios of intense language contact, viz. the contextual categories?

2 As demonstrated in Tables 1 and 2, a sentence merely becomes somewhat ungrammatical if a "redundant" weak category is not marked, but the communication itself does not break down, e.g., German *ich gehen 'I go' instead of the properly inflected verb form of the 1. P. SG. ich gehe. If a strong, "non-redundant" category is used wrongly, the hearer or reader will understand something different, e.g., I ask her (I am doing it now or later) vs. I asked her (I already did it).

3 For Booij, gender on the noun is a category of inherent inflection since it is intrinsic to the noun. I use his terminology with a slightly different meaning which results from the tests applied (see below), and is based on the fact that gender marking in the languages I look at is always outside of the noun itself as part of nominal agreement, thus contextual. The test also leads to the classification of inflectional classes of verbs or nouns as contextual categories. 
Scenarios of language contact that involve (adult, "incomplete" or "imperfect") ${ }^{4}$ second language acquisition (SLA) lead to structural simplifications (e.g., Trudgill 2011b, p. 237). Naturally, the amount of actual simplification is also dependent on the structure of the L1, i.e., if the grammar of an L1 is very similar to the grammar of an L2 in a certain aspect, one would expect a lesser degree of simplification than otherwise. In the following, a certain structural distance between the L1 and the L2 is presupposed. As Kiparsky (1982, p. 99) postulated, weak categories (contextual inflection) are generally more sensitive to morphological erosion than strong categories (inherent inflection). This leads to four hypotheses, the first one of which is the primary focus of the following study, while some initial considerations on the other three hypotheses are also shared:

Hypothesis 1 (H1). Languages that went through periods of intense L2 acquisition in their history tend to contain less contextual categories than closely related languages that did not undergo such periods.

Hypothesis 2 (H2). With respect to inherent features, there is no significant difference between languages that witnessed (strong) L2 effects and languages that did not.

Hypothesis 3 (H3). Languages that witnessed (strong) L2 effects will show an asymmetric distribution of complexity across their categories: there will be a greater imbalance between inherent and contextual features than in other languages.

Hypothesis 4 (H4). Inherent categories might be more strongly associated with the verbal phrase than with the nominal phrase. If that is the case, languages that witnessed (strong) L2 effects would feature an asymmetrical absolute-quantitative complexity between their nominal and their verbal phrase.

\section{Materials and Methods}

In this paper, an absolute-quantitative notion of complexity was used. In this view, linguistic complexity is defined as structural elaboration of the morphosyntactic inventory measured by the number of grammatical categories (Szmrecsanyi and Kortmann 2012, pp. 10-12). Simplification thus means the reduction of grammatical categories, or on a lower level, the reduction of grammatical distinctions within a supercategory (e.g., the change from a four-part case system in Old Norse to a two-part case system in modern Swedish). In counting categories, number 1 means that a category is present, 0 means the absence of a category, and 0.5 means that a category either exists only marginally or is only weakly grammaticalized.

But how to distinguish between inherent and contextual categories? One might be afraid that this dichotomy will generate a lot of cases of doubt when applying it to all kinds of categories, since some categories may be more or less inherent than others. However, it is possible to operationalize the distinction with a simple test:

- If changing the category changes the meaning, the category must be inherent, since it refers to extralinguistic reality;

- If changing the category leads to agrammaticity, the category must be contextual, since it only serves grammatical purposes.

4 The designations "incomplete" or "imperfect" are ideologically loaded, as has been increasingly pointed out in the last few years (Kupisch and Rothman 2018). However, the criticism is mainly directed towards the use of these labels in certain contexts, like in describing bilingual (heritage) speakers. As Kupisch and Rothman (2018, p. 573) admit themselves, this is not the same situation as talking about adult L2 acquisition or "pidgeons" [sic!]. In the latter context, some theories about the genesis of P\&Cs rest on the very concept of incomplete learning. Of course, the labels are not meant to discriminate against anybody but are meant purely descriptively in comparison to structures from an assumed "target language", as the lexifier language is called sometimes (but Baker 1990 on this concept). 
To demonstrate this idea, the test is applied to grammatical features of English in the following tables, separated by nominal domain (Table 1) vs. verbal domain (Table 2).

Table 1. The assignment of nominal categories.

\begin{tabular}{lll}
\hline Feature & Test Examples & Type \\
\hline case & the dog's toy $\left({ }^{*}\right.$ dog toy); ${ }^{*}$ I met he; ${ }^{*}$ for I & contextual \\
gender & Ida asks herself $\left({ }^{*}\right.$ himself) whether ... & contextual \\
number & the dog/the dogs; a book/books & inherent \\
comparative & it is cheap/cheaper/the cheapest & inherent \\
definiteness & the dog is waiting/a dog is waiting & inherent \\
\hline
\end{tabular}

Table 2. The assignment of verbal categories.

\begin{tabular}{lll}
\hline Feature & Test Examples & Type \\
\hline person/number & he goes (*he go); I go (*I goes) & contextual \\
tense (past/future) & you go/went/will go & inherent \\
aspect (progressive/habitual) & he smokes/is smoking/would smoke daily & inherent \\
mood (irrealis) & you can/might go; he goes/he would go & inherent \\
grammatical voice (passive) & the dog bites/is bitten & inherent \\
\hline
\end{tabular}

Looking at the tables, one can already see an interesting tendency: all three contextual features represent residual categories of English that are almost lost (actually, there is no grammatical gender at all, since the remnants in the pronominal system all refer to natural gender). Vice versa, all full categories in English are inherent categories. We will come back to this later.

First and foremost, this paper examined the distribution of inherent and contextual categories across the nominal and verbal phrase in the creole language Unserdeutsch. Unserdeutsch (Rabaul Creole German) is a German-lexified boarding school creole, which emerged at a catholic mission station in Papua New Guinea at the turn of the 19th century during the German colonial period (Volker 1982, pp. 1-15; 1991, pp. 145-49). Its main substrate language is Tok Pisin, while English has exerted an increasing amount of adstrate pressure on the language in recent times after most of its speakers moved to Eastern Australia around 1975. The superstrate of Unserdeutsch is a spoken, only very slightly regionally coloured standard variety of German, which can mainly be located in the north-western part of Germany, especially in the area of Westphalia (Maitz and Lindenfelser 2018). Unserdeutsch represents a case of abrupt language genesis with a clear break in language transmission (Lindenfelser, forthcoming). Compared to the structural complexity of its superstrate language, drastic simplification processes took place in its formation (Lindenfelser and Maitz 2017).

Unserdeutsch has a so-called creole continuum (Maitz 2017), i.e., "vertical" variation ranging from a structurally elaborated style of speech close to its superstrate language to more distant styles of speech with more and more creole features. In this paper, the term "Unserdeutsch" only refers to the basilectal variety of the creole, defined by the variety with the largest distance from the superstrate (the acrolect). ${ }^{5}$ Otherwise, a comparison between the creole and its superstrate would be problematic,

5 An exact definition of the Unserdeutsch basilect based on implicational scaling (DeCamp 1971; Rickford 2004) has not yet been proposed. However, there are certain phonological (e.g., presence or absence of long vowels and certain marked sounds), morphological (e.g., presence or absence of certain synthetic markers, e.g., in nominal plural marking, where the basilect only shows analytic marking) and syntactic (e.g., the extent of so-called bracket constructions, a typological feature of Standard German syntax) features that show a predictive value concerning the distance of a speaker towards the lexifier. As is typical for the scenario of a creole continuum, there is a relatively high amount of not only inter-, but also intraspeaker variation if compared with standardized languages. What counts is whether a feature is productive or not, i.e., used not only with a very small set of most frequent words as is typical for fossilizations due to chunk-based language acquisition (Arnon and Christiansen 2014). 
since there is a flowing transition between the more elaborated varieties of Unserdeutsch and the superstrate itself.

Thus, only the basilectal part (a little more than half of the total amount) of a corpus of more than $50 \mathrm{~h}$ of Unserdeutsch interview data by more than 50 (semi-)speakers ${ }^{6}$ of estimated 100 speakers in total was used in the following study. The full corpus will be made available on the Database for Spoken German (DGD) of the IDS Mannheim soon. ${ }^{7}$ All speakers (with the exception of one speaker who was born in 1961) were older than 65 years. Younger members of the wider language community can be classified as rememberers at most, if at all. All remaining speakers of Unserdeutsch are at least trilingual with full competence in both English as well as Tok Pisin. The Unserdeutsch data were collected as part of a documentation project funded by the German Research Society DFG from 2015 to 2019. The corpus mainly consists of semi-structured sociolinguistic interviews, almost all of which were conducted in small groups of around three to four people, some of them only in pairs. The rest of the data are composed of recorded translations of stimuli from English or Tok Pisin into Unserdeutsch.

\section{Results}

In this chapter, the nominal and verbal domain of Unserdeutsch and its lexifier, spoken Standard German, are compared to each other. Interestingly, the simplification processes already mentioned above eroded the morphosyntactic system of Unserdeutsch in an asymmetric way.

\subsection{The Nominal Domain}

In spoken Standard German, ${ }^{8}$ the superstrate of Unserdeutsch, the noun inflects for three supercategories (gender, case, number) with nine subcategories altogether (three genders, four cases, ${ }^{9}$ two numbers). Additionally, there is the supercategory of definiteness, marked by articles (two subcategories), and the supercategory of comparison on adjectives (three subcategories). Thus, altogether, we have 5 supercategories with 14 values. ${ }^{10}$

In Unserdeutsch, however, the noun only inflects for one supercategory with a bipartite distinction (two numbers). In other words, only $20 \%$ of the original categories of the noun are left. If we include the definiteness and adjectival comparison, we have 3 supercategories with 5.5 subcategories left in Unserdeutsch (superlative is only residual, therefore counted as 0.5), accordingly $40 \%$. There is no grammatical gender (1) and no grammatical case (2) in Unserdeutsch. Moreover, apart from the categories itself, there are no inflectional classes left in Unserdeutsch, while there are weak, strong,

6 English has gradually superseded Unserdeutsch in the now overwhelmingly English-dominated life of most speakers in suburbs of the major cities of Eastern Australia. While some speakers still speak Unserdeutsch fluently, some others show an increasing number of lexical gaps and other attrition phenomena. Today, the use of the language is mainly restricted to private conversations between some of the speakers, larger gatherings of parts of the community, as well as occasions like, due to the advanced age of the speakers, funerals. Even in these last domains, however, English is beginning to replace Unserdeutsch.

7 URL: https://dgd.ids-mannheim.de/DGD2Web/jsp/Welcome.jsp (accessed on 25 October 2020). The finalized corpus version will contain aligned transcripts (transcribed in cGAT, Schmidt et al. 2015) as well as PoS-tagging and comprehensive metadata on the corpus as well as on the speakers. The data have been transcribed and annotated using the EXMARaLDA tools (URL: https://exmaralda.org/en/, accessed on 25 October 2020).

8 Of course, it is important to contrast only the spoken lexifier varieties with the initially exclusively oral contact languages that resulted from them. It would be methodologically highly problematic to compare their features to the categories of the written standard variety.

9 The genitive case seems to be on retreat in (spoken) German, and one could definitely argue for a 0.5 value here, thus 3.5 cases. However, the situation of the genitive case is "more nuanced than the general perception" (Scott 2011, p. 68). The possibilities to substitute the genitive with, especially, dative and prepositional constructions, though widely used, do not seem to dismantle the entrenchment of the genitive case itself in the language system at least for now (e.g., Petig 1997 on genitive prepositions).

10 The counting does not distinguish between synthetic or analytic means of marking, both are treated the same way, e.g., the number category "plural" is expressed synthetically in German (via suffixes), but analytically in Unserdeutsch (via a preceding plural word alle). Since the category is there, both languages receive +1.0 . 
and mixed inflections in the superstrate. The amount of simplification in the nominal domain of Unserdeutsch is substantial.

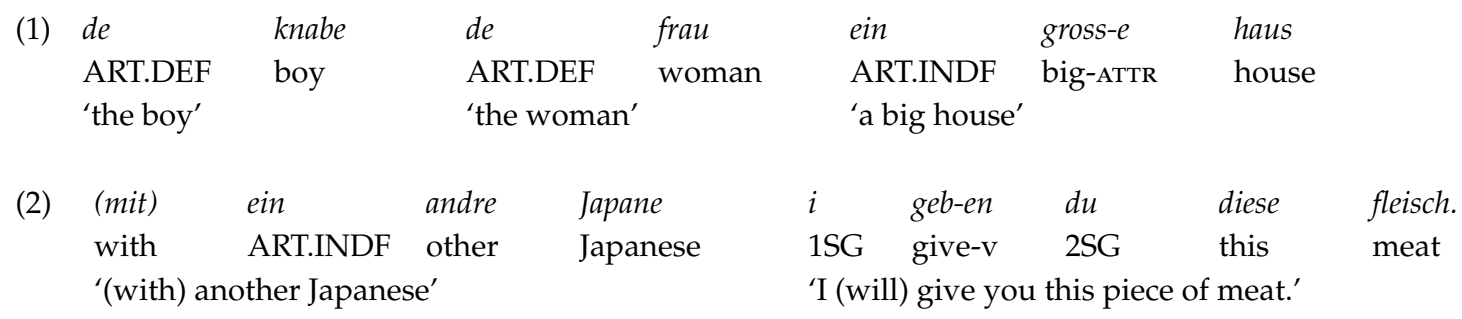

\subsection{The Verbal Domain}

In spoken Standard German, the verb inflects for 5.5 supercategories (person, number, tense, mood, voice, and 0.5 for aspect). Aspect is not counted as a full category of Standard German here: the possibility to mark progressive or habitual aspect with the so-called am-progressive construction in German is definitely a feature of the Standard language nowadays, though it is still highly optional and thus not fully grammaticalised (yet). These 5.5 supercategories consist of, in my counting, 15.5 categories (three persons, two numbers, five tenses, three moods, two voices, and 0.5 for durative aspect). ${ }^{11}$ In Unserdeutsch, the verb inflects for 3.5 supercategories (tense, mood, 0.5 for voice, since the passive voice only appears marginally, and aspect, since the marking of progressive or habitual aspect is obligatory in Unserdeutsch). These 3.5 supercategories consist of, again in my counting, 8.5 categories (three tenses, two moods, 1.5 voices, two aspects). In sum, $55 \%$ of the original verbal categories are preserved in Unserdeutsch. There is past tense (3), future tense (4), irrealis mood (5), progressive-habitual aspect (6), past habitual aspect (7), and the marginal passive voice (8) in Unserdeutsch.

$$
\begin{array}{lllll}
\text { er } & \text { hat } & \text { ge-mah-en } & \text { etwas } & \text { wieder. } \\
\text { 3SG.M } & \text { AUX.PST } & \text { PTCP-make-v } & \text { something } & \text { again }
\end{array}
$$

'He did something again.'

$$
\begin{array}{lllll}
\text { lieb- } a & \text { Gott } & \text { wid } & \text { straf-en } & d u . \\
\text { dear-ATTR } & \text { God } & \text { AUX.FUT } & \text { punish-v } & \text { 2SG }
\end{array}
$$

'The dear God will punish you.'

$\begin{array}{lllll}d u & \text { wid } & \text { ess-en } & \text { was, } & \text { erde? } \\ \text { 2SG } & \text { AUX.IRR } & \text { eat-v } & \text { what } & \text { soil }\end{array}$

'What would you eat, soil?'

(6)

$\begin{array}{llllll}\text { sie } & \text { war } & \text { am } & \text { arbeit-en } & \text { fi } & \text { Quantas. } \\ \text { 3SG.F } & \text { AUX.PST } & \text { PROG/HAB } & \text { work-v } & \text { for } & \text { Quantas }\end{array}$

'She was working for Quantas.'

11 For the sake of simplicity, I only differentiate tense forms that have clear distinct functions. Thereby, I count: present, past (e.g., mainly represented by the perfect in southern German or by the preterite in northern German), anterior (e.g., plusquamperfect forms or double perfect or double plusquamperfect forms), future and future perfect. Mood would be indicative, imperative, and conjunctive mood (mainly represented by the würde-periphrasis in spoken German, substituting the conjunctive II, while the conjunctive I is not actually used because of its syncretism with indicative forms). With respect to aspect, I do not start from an opposition (like durative-non-durative), since the non-use of the not fully grammaticalised am-progressive may still represent a durative form. The assigned values are not meant to give a strong grammatical statement about the categories of Standard German, it is more an attempt to find an easy way of showing a pattern for the comparison. 
(7) $\quad i$

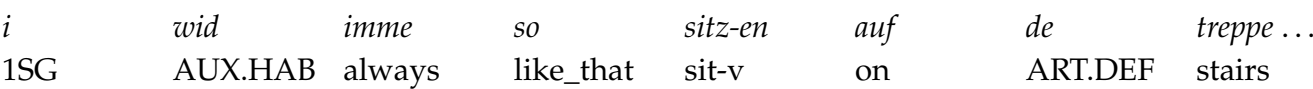

'I would always sit on the stairs like that...'

(8)

$\begin{array}{lllll}\text { alle } & \text { war } & \text { ge-schick } & z u & \text { Vunapope. } \\ \text { everybody } & \text { AUX.PASS } & \text { PTCP-send } & \text { to } & \text { Vunapope }\end{array}$

'Everybody was sent to Vunapope.'

The tense system of Unserdeutsch is reduced and got rid of two secondary tense categories, the complex options of anterior and future perfect. Person and number are not verbal categories anymore in Unserdeutsch, however, the information these categories encode is still indirectly transferred through the subject (and overtly marked in the case of a pronoun in subject position). Therefore, the grammatical information itself, redundantly marked in Standard German, is not lost altogether in Unserdeutsch. The other verbal categories remained largely intact, with the aspect category getting even more elaborated: in addition to the am-construction, there is also the wid-construction in Unserdeutsch, as in (7), that draws on the habitual past function of the English would-construction (Schmidtkunz, forthcoming). ${ }^{12}$

In relation to Standard German, there is a higher loss ${ }^{13}$ of structural complexity in the nominal domain than in the verbal domain. Can this asymmetrical grammatical complexity between NPs and VPs be observed in other pidgin and creole languages (P\&Cs) as well?

\subsection{Comparing Inherent and Contextual Categories}

The presumed categories of (spoken) Standard German and Unserdeutsch have already been counted above, however, they have not been divided according to contextual and inherent categories yet. In what follows, the grammatical categories of both languages will be compared to each other. For this purpose, the categories will be added together on the top-level, thus only counting supercategories (value 1 for a full category, 0.5 for a residuary or not fully-grammaticalized category) and compared to each other. Of course, some borderline cases remain, especially with the assignment of the 0.5 value, where I cannot go into a detailed discussion here. Therefore, it is only about main tendencies. Here are the results (Tables 3 and 4, for small notes on some cases of doubt cf. the two subchapters above).

As one can see from the tables, the main grammatical difference in terms of categories between Standard German and Unserdeutsch is that the latter lost all contextual categories. ${ }^{14}$ In the (short) history of Unserdeutsch, there was an abrupt break in language transmission that led to a lot of L2 simplifications in the language system of Unserdeutsch (Lindenfelser and Maitz 2017). The history of Standard German, on the other hand, only shows a fairly moderate amount of L2 influences on the language. Compared to the Germanic or even the Indo-European protolanguage, some contextual categories got lost (e.g., the case system got reduced by $50 \%$ of the original cases) but some are also still left. Consequently, Unserdeutsch is situated towards the very end of the scale of asymmetrical complexity (and L2 learning involved), while Standard German would be somewhere in the middle.

12 The wit-construction can express future tense (as it does in Standard German), habitual aspect and also irrealis mood. In this respect, it behaves quite similarly to the English would-construction.

13 Speaking about "loss" in this article is not to suggest that something should be there which is not. It also does not suggest that these features have at any given time been part of Unserdeutsch in its development either. It is only meant in a descriptive sense, i.e., that some features have not been transferred from the lexifier language (whereas others have been). In using this term, I adhere to e.g., Muysken (2016, sct. 5): "All or most researchers will agree that certain distinctions that exist in the lexifiers have been lost in the corresponding creole languages [ ... ]."

14 One could argue that there is half (or quarter?) of a contextual category in Unserdeutsch: The possibility of marking transitivity on verbs with the suffix \{-im\}, taken over from Tok Pisin. However, this firstly only applies to a small subset of verbs (verbs directly borrowed from English), secondly, the marking is always optional and, thirdly, only some speakers use it. That is why I do not take it into consideration here. 
Unserdeutsch also shows even less contextual inflection (0.0) than its adstrate language English (1.0, cf. chapter 5), which itself supposedly underwent some L2-simplification processes, which in turn cannot have been as dramatic as in the case of Unserdeutsch. It even shows less contextual inflection than its substrate language Tok Pisin (1.0, chapter 5), although Tok Pisin underwent abrupt pidginization processes itself.

Table 3. The grammatical categories of (spoken) Standard German.

\begin{tabular}{cccccc}
\hline Inherent Categories & $\mathbf{N} / \mathbf{V}$ & Value & Contextual Categories & $\mathbf{N} / \mathbf{V}$ & Value \\
\hline number & $\mathrm{N}$ & 1.0 & case & $\mathrm{N}$ & 1.0 \\
adjectival comparison & $\mathrm{N}$ & 1.0 & gender & $\mathrm{N}$ & 1.0 \\
definiteness & $\mathrm{N}$ & 1.0 & & & \\
tense (past/future) & $\mathrm{V}$ & 1.0 & person/number & $\mathrm{V}$ & 1.0 \\
aspect (prog./hab.) & $\mathrm{V}$ & 0.5 & & \\
mood (irrealis) & $\mathrm{V}$ & 1.0 & & \\
voice (passive) & $\mathrm{V}$ & 1.0 & sum: $\mathbf{6 . 5}$ inherent/3.0 contextual \\
\hline
\end{tabular}

Table 4. The grammatical categories of Unserdeutsch.

\begin{tabular}{cccccc}
\hline Inherent Categories & $\mathrm{N} / \mathrm{V}$ & Value & Contextual Categories & $\mathbf{N} / \mathbf{V}$ & Value \\
\hline number & $\mathrm{N}$ & 1.0 & & \\
adjectival comparison & $\mathrm{N}$ & 1.0 & & \\
definiteness & $\mathrm{N}$ & 1.0 & & \\
tense (past/future) & $\mathrm{V}$ & 1.0 & & \\
aspect (prog./hab.) & $\mathrm{V}$ & 1.0 & & \\
mood (irrealis) & $\mathrm{V}$ & 1.0 & & \\
voice (passive) & $\mathrm{V}$ & 0.5 & sum: $\mathbf{6 . 5}$ inherent/0.0 contextual \\
\hline
\end{tabular}

\section{Some Categorical Preferences in Pidgin and Creole Languages}

Based on the APiCS (Atlas of Pidgin and Creole Language Structures, Michaelis et al. 2013) database, including 76 languages, as well as on Holm and Patrick (2007) with comparative grammatical sketches of $18 \mathrm{P} \& \mathrm{Cs}$, it is noticeable that $80 \%$ of the P\&Cs have no gender or case marking in the NP, including Unserdeutsch. With respect to gender, the remaining $20 \%$ of the P\&Cs moreover only have partial or residual gender marking. ${ }^{15}$ On the other hand, nominal plural marking is present in $93 \%$ of the P\&Cs, just like in Unserdeutsch again. Marking of definiteness is also present in $88 \%$ of the P\&Cs, as it is in Unserdeutsch.

Regarding the verbal categories, the vast majority of $\mathrm{P} \& \mathrm{Cs}$ feature the same verbal categories that are fully preserved (or even extended) in Unserdeutsch: $94 \%$ of the P\&Cs mark progressive aspect, $78 \%$ mark habitual aspect, $83 \%$ mark past tense (and/or completive aspect), and $89 \%$ mark future tense (and/or irrealis mood). ${ }^{16}$ On the other hand, $79 \%$ of the pidgin languages have no person/number marking at all (Roberts and Bresnan 2008), which is also absent in Unserdeutsch. Now, the question arises: why do these tendencies occur in P\&Cs?

With the study of Roberts and Bresnan (2008), there is already some evidence for the first three hypotheses formulated in Chapter 2. The authors conducted a quantitative analysis of 29 pidgin languages and found that in pidgins, compared to their lexifiers,

15 There is only one exception in the APiCS database with full gender marking on adjectives, Mixed Ma'a/Mbugu-which, however, is no pidgin or creole, but a mixed language. This is important, since mixed languages typically do not show traces of intense L2 learning because of the speakers' bilingualism.

16 In the feature discussions of Holm and Patrick (2007), past tense and completive aspect as well as future tense and irrealis mood are taken together because of their somehow related semantics. 
"contextual" inflections such as case markings on nouns and nominal agreement on verbs are retained slightly less often than "inherent" inflections such as number and definiteness on nouns and tense and aspect on verbs. (Roberts and Bresnan 2008, p. 271) ${ }^{17}$

This supports HYP-1. They also found that "[d]espite the heavy loss of inflection in pidgin genesis, a greater proportion of inherent reflections [sic!] are retained than contextual inflections" (Roberts and Bresnan 2008, p. 287), which supports HYP-2. Consequently, the data on pidgin languages also suggest HYP-3, namely that "the reduction of inflection is asymmetric" (Roberts and Bresnan 2008, p. 293).

Kihm (2003) and Plag $(2008,2013)$ have argued and demonstrated that creole languages similarly show a strong tendency to retain inherent categories but drop contextual categories. Therefore, "creole languages exhibit little or no contextual inflection in comparison with the lexifier or substrate languages" (Kihm 2003, p. 335). The same conclusion has been drawn by Bakker and Daval-Markussen (2017, pp. 83-85):

The evidence reviewed [ ... ] suggests a complete absence of inherited contextual inflection in creoles, but some inherent inflection is inherited from the lexifiers or grammaticalized (see Holm 2008; Luís 2010). Still, compared to global samples of languages, creoles are found nearly invariably at one end of the spectrum, i.e., closer to languages with no inflectional morphology than to polysynthethic languages [ ... ]. (Bakker and Daval-Markussen 2017, p. 85)

Plag's explanation (2008) for this finding is that creoles mostly have interlanguage morphology of an early stage. Since contextual inflection is based on syntactic connections (e.g., agreement marking), the use of contextual inflection presupposes an understanding of (complex) phrasal structure, while inherent inflection is understandable on its own (also Plag 2013, p. 145). ${ }^{18}$ Hence, inherent categories come earlier in the learning process and would be the first categories to be transferred into pidgins/creoles with heavy L2 learning involved. ${ }^{19}$

There also seems to be a significant difference in the mastery of contextual categories when comparing bilingual children and adult L2 learners; e.g., with regard to the gender category (here: Swedish/French), children made only around 5\% gender errors, while the adult L2 learners error rate was around 25\% (Franceschina 2005, p. 116, on a study of Granfeldt 2000). This would again underline the possible influence of the "lousy language-learning abilities of the human adult" (Trudgill 2001, p. 372) on language systems.

On the other hand, the tendency to retain inherent categories can be explained,

simply because tense, aspect, number, etc., are necessary for the adequate expression of the events and states human beings have to communicate to each other about. (Kihm 2013, p. 11)

Setting up a cline ranging from few or even no contextual categories to many contextual categories, P\&Cs would be on the one end of the scale, ${ }^{20}$ while some languages with a long and steady tradition involving no L2 learning would be on the other end of the scale. The intermediate range would be covered by languages with different degrees of L2 learning involved.

17 The authors conform to the use of the terms by Booij $(1993,1995)$, thereby classifying grammatical gender as an inherent category. However, the overall results would not change otherwise.

18 This is again an argument to treat the category gender as belonging to the contextual type, since "gender is encoded at a syntactic processing stage" (Franceschina 2005, p. 102).

19 In this article, the term (adult) L2 learning refers to learning processes that take place after the (childlike) L1 acquisition of one or, in the case of bilingualism, two first languages. Speaking in terms of the critical (or maybe better: sensitive) period hypothesis (Lenneberg 1967), the term L2 learning here refers to learning after this period (though it is controversial, when exactly that period ends: The ages of six or seven years have often been invoked, but also twelve years for instance).

20 Within the category of $\mathrm{P} \& \mathrm{Cs}$, the individual languages could furthermore be arranged according to their "radicalness" (which is associated with a higher occurrence of prototypical, typologically simple creole features), as shown by Daval-Markussen (2017) for 12 French-based creoles and their structural distance from their lexifier. 
The underlying, albeit still heavily discussed idea ${ }^{21}$ within Creole studies that P\&Cs generally score rather low on a scale of (absolute-quantitative) complexity due to heavy L2 learning is supported, e.g., by the quantitative study of Parkvall (2008). Parkvall shows that P\&Cs score significantly lower when compared to the languages of the WALS database (Dryer and Haspelmath) and concludes:

A comparison of the complexity found within pidgins, expanded pidgins, creoles and other languages shows that the complexity of a language correlates with its age. This is precisely what is predicted by the scenario (the most well-known being that set out in McWhorter (2001) in which creoles emerge through broken transmission, and where complexity accretes over time. (Parkvall 2008, p. 283, emphasis in the original)

\section{Structural Complexity in Two Further Language Pairs}

In what follows, two further genetically related language pairs are compared to each other, applying the same method that has already been used in Chapter 4.3 to compare Unserdeutsch with Standard German. These two language pairs will be regarded more closely, further pairs from other language families are then only mentioned with short references to the simplification tendencies that can be observed in the transition from one language to the other. Standard German as a highly inflecting language within the Germanic language family has already been compared to its quite isolating creole Unserdeutsch. Now, English as an already quite isolating language will be compared to its expanded pidgin Tok Pisin, which is even more isolating. In another case study, the relatively highly inflecting language Dutch will be compared with Afrikaans, which has sometimes been called a "semi-creole", since the structural reduction is clearly visible but not anywhere near the structural reduction of Unserdeutsch or Tok Pisin compared to their lexifier languages.

\subsection{English and Tok Pisin}

English (Table 5) has already been treated in Chapter 4, however, without counting the categories. It will be compared to the English-based expanded pidgin (or creole, depending on classification) ${ }^{22}$ Tok Pisin (Table 6), the national language of Papua New Guinea, which is also the main substrate language of Unserdeutsch. On the other side, there is Old English, which was far more complex in its grammatical system than present-day English (O'Neil 1978, p. 249: "the complex inflectional system of Old English was largely and rapidly neutralized on contact with the complex inflectional system of Old Norse").

English has only one contextual category. The rest got eliminated during the transition from Old English to Middle English (Trudgill 2010, chapter "What really happened to Old English?"), which obviously included adult L2 learning of Old English (Trudgill 2010, pp. 31-35). The L2 learning seems to be the reason for the loss of contextual categories during that time. The processes that took

21 The possibility of P\&Cs being simpler than non-pidgins and non-creoles by overall tendency implies the existence of a typological class of pidgins and creoles in the first place. Even this assumption is highly controversial within Creole studies, as can easily be seen from the titles of only two publications on this topic: "Creoles are typologically distinct from non-creoles" (Bakker et al. 2011)—vs. "Creoles are not typologically distinct from non-creoles" (Fon Sing 2017), both quantitative studies based on the computation of phylogenetic networks. In this paper, I adhere to the view that P\&Cs form a separate typological class (though with fuzzy boundaries), e.g., in line with the large-scale quantitative studies of Daval-Markussen (2018) as well as Blasi et al. (2017) and the synopsis of Daval-Markussen and Bakker (2017) on this topic. Note that Blasi et al. (2017) do not ascribe their findings to a break in transmission during L2 learning, but to the similarity of the contact languages involved in P\&C scenarios, as supported by the design of their study: "While a creole profile can be detected statistically, this stems from an over-representation of Western European and West African languages in their context of emergence." (p. 723)

22 Most scholars treat Tok Pisin (also: New Guinea Pidgin) as an expanded pidgin, which means that it fulfills similar linguistic functions to a creole, but is not the L1 of an entire speech community (more than $95 \%$ of all speakers of Tok Pisin only use it as a second language, Ethnologue 2019 [= Eberhard et al. 2019], entry Tok Pisin). 
place in the transitional period can best be described as an instance of koineization, as was done by Dawson (2003). This goes far beyond the changes from, e.g., Old High German to New High German. ${ }^{23}$

Table 5. The grammatical categories of modern English.

\begin{tabular}{cccccc}
\hline Inherent Categories & $\mathbf{N} / \mathbf{V}$ & Value & Contextual Categories & N/V & Value \\
\hline number & $\mathrm{N}$ & 1.0 & case & $\mathrm{N}$ & 0.5 \\
adjectival comparison & $\mathrm{N}$ & 1.0 & & & \\
definiteness & $\mathrm{N}$ & 1.0 & & $\mathrm{~V}$ & 0.5 \\
tense (past/future) & $\mathrm{V}$ & 1.0 & person/number & & \\
aspect (prog./hab.) & $\mathrm{V}$ & 1.0 & & \\
mood (irrealis) & $\mathrm{V}$ & 1.0 & & \\
voice (passive) & $\mathrm{V}$ & 1.0 & sum: $\mathbf{6 . 5}$ inherent/1.0 contextual \\
\hline
\end{tabular}

Table 6. The grammatical categories of Tok Pisin.

\begin{tabular}{cccccc}
\hline Inherent Categories & $\mathrm{N} / \mathrm{V}$ & Value & Contextual Categories & N/V & Value \\
\hline number & $\mathrm{N}$ & 1.0 & transitivity & $\mathrm{N}$ & 1.0 \\
adjectival comparison & $\mathrm{N}$ & 0.5 & & \\
definiteness & $\mathrm{N}$ & 0.5 & & \\
tense (past/future) & $\mathrm{V}$ & 1.0 & & \\
aspect (prog./hab.) & $\mathrm{V}$ & 1.0 & sum: $\mathbf{4 . 0}$ inherent/1.0 contextual \\
\hline
\end{tabular}

Tok Pisin, which features a break in language transmission and therefore heavy L2 learning, got rid of all the remnants of contextual categories that were still left in English and, since the simplification was quite radical, also some of the inherent categories. At the same time, Tok Pisin took over the transitive marking from its substrate language Kuanua (Tolai), thus ending up with still one contextual category. Still, compared to Kuanua, Tok Pisin did not take over another contextual inflectional feature from it like the obligatory, inflectable subject marker of Kuanua with 16 different forms (plus various variants) depending on the independent subject pronoun used (Mosel 1984, p. 93). In Tok Pisin, only the invariant, thus not inflectable subject marker $i$ is left (derived from the 3. P. SG. form of the Kuanua paradigm). The inherent distinctions of the complex pronominal system of Kuanua (featuring dual and trial forms as well as an inclusive/exclusive distinction within the 1. P. PL. pronoun), again, got fully transferred to the pronominal system of Tok Pisin.

\subsection{Dutch and Afrikaans}

It is interesting to compare Dutch (Table 7) with Afrikaans (Table 8), since Afrikaans is not considered a creole but nevertheless underwent adult L2 acquisition in its history.

Not surprisingly, Dutch compares to Standard German with regard to its complexity but with a few minor reductions (especially on sub-category level). Afrikaans however, has lost all contextual categories but not the inherent ones (e.g., Donaldson 1993; Conradie 2001). The genesis of Afrikaans has been "heavily conditioned by nonwhites who learned Dutch imperfectly as a second language" (Thomason and Kaufman 1988, p. 256). Afrikaans is sometimes treated as a semi-creole. McWhorter (2014, pp. 104-5) points out structural similarities between Afrikaans and English and concludes that "there is no reason that English not be classified as semi-creole as well". This also underlines the role of L2 learning in both languages.

23 Although rightly rejected by almost all scholars nowadays, even creolization (Bailey and Maroldt 1977; Danchev 1997) as well as an interlanguage status (Danchev 1986) have been discussed for this period, which never has been even thought of for the development of German. 
Table 7. The grammatical categories of Dutch.

\begin{tabular}{cccccc}
\hline Inherent Categories & $\mathrm{N} / \mathrm{V}$ & Value & Contextual Categories & $\mathbf{N} / \mathbf{V}$ & Value \\
\hline number & $\mathrm{N}$ & 1.0 & case & $\mathrm{N}$ & 0.5 \\
adjectival comparison & $\mathrm{N}$ & 1.0 & gender & $\mathrm{V}$ & 1.0 \\
definiteness & $\mathrm{N}$ & 1.0 & & & \\
tense (past/future) & $\mathrm{V}$ & 1.0 & person/number & $\mathrm{V}$ & 1.0 \\
aspect (prog./hab.) & $\mathrm{V}$ & $1.0^{24}$ & & & \\
mood (irrealis) & $\mathrm{V}$ & 1.0 & & \\
voice (passive) & $\mathrm{V}$ & 1.0 & sum: 7.0 inherent/2.5 contextual \\
\hline
\end{tabular}

The seemingly most important substrate language of Afrikaans is the Khoekhoe language (also called Nama/Damara), ${ }^{25}$ which belongs to the Khoe language family and is the most widespread non-Bantu language in the southern part of Africa. The Khoekhoe grammar exhibits a considerable amount of contextual inflection, which in the case of its three-gender system (Hagman 1977, pp. 22-26) is even basically compatible with the Dutch system, with both featuring a feminine, masculine, and neuter distinction. Additionally, Khoekhoe features a case system with two cases according to Hagman (1977, pp. 36-37, 41-45), or even four different cases according to the analysis of Haacke (1976, p. 174). Although the existence of both a gender as well as a case system in the most important substrate language of Afrikaans is compatible with their existence in the lexifier language Dutch, both are still absent in Afrikaans.

Table 8. The grammatical categories of Afrikaans.

\begin{tabular}{cccccc}
\hline Inherent Categories & N/V & Value & Contextual Categories & N/V & Value \\
\hline number & $\mathrm{N}$ & 1.0 & & \\
adjectival comparison & $\mathrm{N}$ & 1.0 & & \\
definiteness & $\mathrm{N}$ & 1.0 & & \\
tense (past/future) & $\mathrm{V}$ & 1.0 & & \\
aspect (prog./hab.) & $\mathrm{V}$ & 0.5 & & \\
mood (irrealis) & $\mathrm{V}$ & 1.0 & & \\
voice (passive) & $\mathrm{V}$ & 1.0 & sum: $\mathbf{6 . 5}$ inherent/0 contextual \\
\hline
\end{tabular}

\subsection{Further Language Pairs}

In his inspiring book about "signs of non-native acquisition in standard language grammars", McWhorter (2007) deals with pairs of standard languages beyond the extreme pole of P\&Cs. He shows convincingly that the presence of a large amount of adult L2 learners broke down the grammatical complexity of the considered languages. One example is Persian, which in its change from Old Persian to present age lost its three genders, six cases, and several declension classes (McWhorter 2007, p. 138), while its sister languages retained far more structural complexity. A possible explanation might be seen in the fact that the vast former empire in the region has been "documented as having been a vibrantly multiethnic one" (McWhorter 2007, p. 163), which indicates extensive L2 learning.

Another example would be the transition from Classical Arabic to the new Arabic varieties of the present (McWhorter 2007, pp. 165-96), whereby again nominal case and gender distinctions got lost in a language ecology coined by "rapid and massive population movements" (McWhorter 2007, p. 196) and consequently L2 learning. Owen (2013, p. 454), in summarizing the positions of Fück (1950) and Ferguson (1959), talks about simplifications due to "massive influxes of non-native speakers" resp.

24 There is an ongoing discussion as to which degree Dutch is already an aspect language, however, the progressive construction in Dutch is far more grammaticalized than in German (Behrens et al. 2013).

25 For evidence of substantial substrate transfer from the Khoekhoe system to Afrikaans in the context of L2 acquisition of the latter (resp. Dutch) through L1 Khoekhoe speakers, e.g., den Besten (2002). 
the development of a "simplified koine" in the transition from Classical Arabic to the new Arabic varieties. Versteegh (1984) explicitly uses the notions of "pidginization" and "creolization" to refer to the linguistic processes that took part during this transition.

Malay, which "has been one of the world's most widely spoken lingua francas for most of its existence" (McWhorter 2007, p. 251) and thus constitutes a perfect example of "long-term non-native acquisition" (McWhorter 2007), shows a striking amount of simplifications in comparison to its linguistic ancestors as well as some related languages in the present. Examples of contextual features that got lost in Malay are agreement marking, verb classes based on transitivity (McWhorter 2007, p. 211), and a number of numeral classifiers (compared to other Indonesian-type languages) got lost (McWhorter 2007, p. 209).

A similar example is the case of Mandarin, which in comparison to other Chinese languages that underwent less L2 learning, lost the last few remnants of grammatical gender marking, for example (McWhorter 2007, p. 117).

Last but not least, if we compare Latin (via its non-standard sociolects of spoken Vulgar Latin) to its successors, the Romance languages of today, with regard to structural complexity (McWhorter 2007, pp. 269-72), the erosion of the Latin case categories also fits the picture: there was moderate L2 learning during the historical transmission, and thus also a moderate amount of simplification with regard to contextual categories. In particular, the case category and, in most Romance languages, also the Latin neuter gender disappeared. With verbs, the situation is similar: "the rich Latin verbal morphology is generally reduced in Romance" (Kabatek and Pusch 2011, p. 76). ${ }^{26}$

These examples given by John McWhorter underline once more the assumption that there might be a correlation between the amount of L2 learning and the loss of contextual features. However, as follows from McWhorter's descriptions, inherent features can fade away as well. Perhaps, once all contextual features are eroded, inherent features are the next target of reduction. In cases of drastically interrupted language transmission, they might also be affected from the very beginning but with less dramatic consequences, since they seem to be more resistant to the eroding forces of L2 effects.

\section{Discussion}

Up to this point, there have been some indications that there is an asymmetry with regard to contextual vs. inherent categories in languages that underwent widespread L2 learning. But can this difference also be mapped onto phrasal types, meaning that the NP or VP might be linked with one of the two types of grammatical categories to a greater extent than with the other?

Proceeding from a broad understanding of "nominal categories", there does not seem to be any difference in the affinity of contextual or inherent categories to verbal or nominal phrases if one takes a look at the tables presented above. But since the nominal categories are a quite heterogenous class, featuring also adjectives, articles, and pronouns, it might be more promising to just compare verbs with nouns. Doing that, two aspects can be observed from the tables (of course, this is only a cautious first approximation, since the languages considered are not representative of the world's large variety of languages):

(a) Generally, more categories seem to be affiliated with the verb than with the noun;

(b) There might be a preference for inherent categories in the verbal phrase compared to categories of the noun.

An interesting instance is plural marking that appears on verbs as well as on nouns. Verb pluralization, on the one hand, is a contextual category, and often the only verbal contextual

26 Simplification processes during the transition from Latin to the modern Romance languages are also observed on the phonological level (Kabatek and Pusch 2011, p. 73). With regard to observable segmental reduction, Vaissière writes, "one may argue that the language [here: French, S.L.] got rid of all syllables unnecessary for communication" (Vaissière 1996, p. 70). 
category in Indo-European languages. Noun pluralization, on the other hand, is an inherent category, and, again, in Indo-European languages often the only nominal inherent category. Thus, in scenarios involving intense L2 learning, usually the plural marking remains intact for nouns, but disappears on verbs (Booij 1993, p. 33, already noted).

Dressler (2007, pp. 5-6) compared the paradigmatic morphological richness of nine different languages (three agglutinating, three strongly inflecting, and three weakly inflecting). His results show that the number of verbal form-type categories is higher than the number of form-type categories on the noun in all nine languages, reinforcing observation (a).

Comparing the feature lists for verbal categories and nominal categories in WALS (Dryer and Haspelmath), observation (b) seems to be confirmed, too: apart from the features that have already been discussed, all kinds of numeral classifiers or noun class markers, both features of nouns, belong to the realm of contextual features. On the other hand, all further categories of mood (like prohibitive, optative, etc.), of aspect, of tense, and also all categories of evidentiality belong to the realm of inherent features. Therefore, verbs seem to be stronger affiliated with inherent categories, while nouns are generally stronger affiliated with contextual categories.

In discussion, Dressler et al. $(2007$, p. 70$)$ found a very interesting link to the speed of acquisition of verb and noun inflection:

As far as the speed of early development of inflectional paradigms is concerned, our results are unequivocal: in all languages of our sample speed of development is higher in verb inflection than in noun inflection, even when there is a time lag between the earlier construction of noun and that of verb paradigms. This may be explained by the greater communicative importance of verb inflection as compared to noun inflection within each of our nine languages, which may also be the main reason for the existence of more morphological categories in the verb than in the noun. (Dressler et al. 2007, p. 70)

If verbal inflection is more strongly associated with inherent categories and, at the same time, acquired faster than noun inflection, then indeed languages with visible L2 effects in their systems should show a structural asymmetry: there should be a universal tendency for them to have more verbal categories than noun categories (still leaving other nominal categories aside here that would further complicate the issue). For the languages considered here, this tendency clearly applies.

\section{Conclusions}

In sum, there seems to be a considerable amount of evidence for HYP-1, suggesting that contextual categories erode under the influence of L2 acquisition. The evaluation of HYP-2 is more difficult: under conditions of strong L2 effects, inherent categories obviously are also affected by erosive powers. However, the process seems to be delayed and weakened for these categories, compared to contextual categories. A quantitative study of L2 effects on the erosion especially of inherent categories is a desideratum. Consequently, there is also indication for HYP-3 to be accurate, namely that there is an asymmetrical distribution of complexity between contextual and inherent categories in languages that experienced (intense, adult) L2 learning. HYP-4 would be a candidate for a large-scale quantitative study: there is some evidence pointing to an asymmetry also between the complexity of noun vs. verb categories in such languages, however, this would have to be confirmed for a much bigger language sample.

Counting the number of categories, as done in the comparison of selected language pairs in this paper, makes it possible to arrange languages on a scale, e.g., with reference to their number of (retained) contextual categories. Matching the results with the known historical facts about periods of possible widespread/intense L2 acquisition in the history of the respective language may answer the question of whether there is a correlation between the number of contextual categories present on the one hand and the strength of operative L2 effects on the other hand. The scale for the language pairs 
regarded in this paper would be the following (with inherent categories considered in sorting in the case of an equal amount of contextual categories): ${ }^{27}$

$$
\text { Unserdeutsch/Afrikaans (0) - Tok Pisin (1) - English (1) - Dutch (2.5) - German (3). }
$$

As can be seen from this, the factor of substrate influence, potentially leading to the rise of new contextual categories via transfer (as with the transitivity marker in the case of Tok Pisin) needs to be considered, too, as well as the entire number of categories (which is lower in Tok Pisin than in Afrikaans). Apart from this small correction, the order of the languages based on their number of (grammatical) contextual categories definitely corresponds to the intuitive assumption on the amount of L2 effects to be expected in the system of these languages. Again, however, large-scale quantitative studies going beyond the realm of $\mathrm{P} \& \mathrm{C}$ s would be desirable to further test the hypotheses. The concept of measuring something like a "contextuality index" may also be transferred to other areas of grammar, especially to the area of syntax: in syntax, there are also changes that indicate another extra-linguistic meaning (e.g., a different serialisation, when a sentence is to be understood as a question or an imperative in German), whereas other changes only serve grammatical reasons (e.g., different serialisation in most types of subordinate clauses versus the serialisation in the main clause in German). The latter case would further increase the "contextuality index" of a given language, while the former example rests on a difference in meaning and would thus contribute to the "inherentness index". In Unserdeutsch, tellingly, there are no rests of any different serialisation between main and subordinate clauses, while there are in fact some remnants of the lexifier serialisation in question or imperative clauses.

Funding: The underlying research of this article was supported by a German Research Foundation (DFG) grant (MA 6769/1-1) as well as a travel grant by the German Academic Exchange Service (DAAD).

Conflicts of Interest: The author declares no conflict of interest.

\section{References}

Arnon, Inbal, and Morten H. Christiansen. 2014. Chunk-based language acquisition. In Encyclopedia of Language Development. Edited by Patricia J. Brooks and Vera Kempe. Thousand Oaks: Sage, pp. 88-90.

Atkinson, Mark, Kenny Smith, and Simon Kirby. 2018. Adult learning and language simplification. Cognitive Science 42: 2818-54. [CrossRef]

Bailey, Charles-James, and Karl Maroldt. 1977. The French lineage of English. In Pidgins-Creoles-Languages in Contact. Edited by Jürgen M. Meisel. Tübingen: TBL, pp. 21-53.

Baker, Philip. 1990. Off target? Journal of Pidgin and Creole Languages 5: 107-19. [CrossRef]

Bakker, Peter, and Aymeric Daval-Markussen. 2017. Creole typology I: Comparative overview of creole languages. In Creole Studies_Phylogenetic Approaches. Edited by Peter Bakker, Finn Borchsenius, Carsten Levisen and Eeva Sippola. Amsterdam/Philadelphia: Benjamins, pp. 79-101.

Bakker, Peter, Aymeric Daval-Markussen, Mikael Parkvall, and Ingo Plag. 2011. Creoles are typologically distinct from non-creoles. Journal of Pidgin and Creole Languages 26: 5-42. [CrossRef]

Behrens, Bergljot, Monique Flecken, and Mary Carroll. 2013. Progressive attraction: The use and grammaticalization of progressive aspect in Dutch, Norwegian and German. Journal of Germanic Linguistics 25: 95-136. [CrossRef]

27 This scale is only depicted here for illustrative reasons in order to indicate how languages may be ordered based on the number of contextual categories they show. For a more valid sorting, the method would need to be more fine-grained and should not only consider morphological categories. Thus, it is not intended here to say anything about the overall morphological complexity of these languages. On the contrary, language contact may of course also lead to the formation of some non-simplifying, even complexifying features (through direct transfer or through what is discussed as "innovations" in creole studies, i.e. mainly through new grammaticalization processes). In this paper, however, the focus lies on the aspect of simplification, which seems to be the overall tendency in these scenarios, where adult language learning is involved (also the experimental results of Atkinson et al. 2018). 
Blasi, Damían E., Susanne Maria Michaelis, and Martin Haspelmath. 2017. Grammars are robustly transmitted even during the emergence of creole languages. Nature Human Behaviour 1: 723-29. [CrossRef] [PubMed]

Booij, Geert. 1993. Against split morphology. In Yearbook of Morphology 1993. Edited by Geert Booij and Jaap van Marle. Dordrecht/Boston/London: Kluwer, pp. 27-49.

Booij, Geert. 1995. Inherent versus contextual inflection and the split morphology hypothesis. In Yearbook of Morphology 1995. Edited by Geert Booij and Jaap van Marle. Dordrecht/Boston/London: Kluwer, pp. 1-16.

Conradie, Jac C. 2001. Isomorphism and language change. In Historical Linguistics 2001: Selected Papers from the 15th International Conference on Historical Linguistics. Edited by Barry J. Blake and Kate Burridge. Amsterdam/Philadelphia: Benjamins, pp. 71-85.

Corbett, Greville G. 2006. Agreement. Cambridge: Cambridge University Press.

Danchev, Andrei. 1986. Interlanguage simplification in Middle English vowel phonology? In Linguistics across Historical and Geographical Boundaries. Edited by Dieter Kastovsky and Aleksander Szwedek. New York: Mouton de Gruyter, pp. 239-52.

Danchev, Andrei. 1997. The Middle English creolization hypothesis revisited. In Studies in Middle English Linguistics. Edited by Jacek Fisiak. New York: Mouton de Gruyter, pp. 79-108.

Daval-Markussen, Aymeric. 2017. The typology and classification of French-based creoles: A global perspective. In Creole Studies-Phylogenetic Approaches. Edited by Peter Bakker, Finn Borchsenius, Carsten Levisen and Eeva Sippola. Amsterdam/Philadelphia: Benjamins, pp. 175-91.

Daval-Markussen, Aymeric. 2018. Reconstructign Creole. Ph.D. dissertation, Aarhus University, Aarhus, Denmark.

Daval-Markussen, Aymeric, and Peter Bakker. 2017. Creole typology II: Typological features of creoles. From early proposals to phylogenetic approaches and comparisons with non-creoles. In Creole Studies_Phylogenetic Approaches. Edited by Peter Bakker, Finn Borchsenius, Carsten Levisen and Eeva Sippola. Amsterdam/Philadelphia: Benjamins, pp. 103-40.

Dawson, Hope C. 2003. Defining the outcome of language contact: Old English and Old Norse. OSUWPL 57: 40-57.

DeCamp, David. 1971. Toward a generative analysis of a post-creole speech continuum. In Pidginization and Creolization of Languages. Edited by Dell Hymes. Cambridge: Cambridge University Press, pp. 349-70.

den Besten, Hans. 2002. Khoekhoe syntax and its implications for L2 acquisition of Dutch and Afrikaans. In Focus on Afrikaans Sociohistorical Linguistics, Part II (= Journal of Germanic Linguistics 14). Edited by Rajend Mesthrie and Paul T. Roberge. Cambridge: Cambridge University Press, pp. 3-56.

Dixon, Robert M. W. 2016. Are Some Languages Better than Others? Oxford: Oxford University Press.

Donaldson, Bruce C. 1993. A Grammar of Afrikaans. Berlin/New York: Mouton de Gruyter.

Dressler, Wolfgang U. 2007. Introduction. In Typological Perspectives on the Acquisition of Noun and Verb Morphology (= Antwerp Papers in Linguistics 112). Edited by Sabine Laaha and Steven Gillis. Antwerpen: Department of Linguistics of the University of Antwerp, pp. 3-10.

Dressler, Wolfgang U., Ursula Stephany, Ayhan Aksu-Koç, and Steven Gillis. 2007. Discussion and conclusion. In Typological Perspectives on the Acquisition of Noun and Verb Morphology (= Antwerp Papers in Linguistics 112). Edited by Sabine Laaha and Steven Gillis. Antwerpen: Department of Linguistics of the University of Antwerp, pp. 67-72.

Dryer, Matthew S., and Martin Haspelmath, eds. The World Atlas of Language Structures Online. Leipzig: Max Planck Institute for Evolutionary Anthropology, Available online: http://www.wals.info (accessed on 25 October 2020).

Eberhard, David M., Gary F. Simons, and Charles D. Fennig. 2019. Ethnologue: Languages of the World, 22 th ed. Dallas: SIL International, Available online: http://www.ethnologue.com (accessed on 25 October 2020).

Ferguson, Charles. 1959. The Arabic koine. Language 35: 16-630. [CrossRef]

Fon Sing, Guillaume. 2017. Creoles are not typologically distinct from non-Creoles. Language Ecology 1: 44-74. [CrossRef]

Franceschina, Florencia. 2005. Fossilized Second Language Grammars: The Acquisition of Grammatical Gender. Amsterdam/Philadelphia: Benjamins.

Fück, Johann. 1950. Arabiya. Berlin: Akademie.

Granfeldt, Jonas. 2000. Le Développement Morphosyntactique du Syntagme Nominal chez des Enfants et des Adultes-Approche Générativiste (= PERLES 9). Lund: Université de Lund. 
Haacke, Wilfri. 1976. A Nama Grammar: The Noun-Phrase. Master's thesis, University of Cape Town, Cape Town, South Africa.

Hagman, Roy Stephen. 1977. Nama Hottentot Grammar. Bloomington: Indiana University Press.

Holm, John A., and Peter L. Patrick. 2007. Comparative Creole Syntax. Parallel Outlines of 18 Creole Grammars. London: Battlebridge.

Kabatek, Johannes, and Claus D. Pusch. 2011. The Romance languages. In The Languages and Linguistics of Europe. A Comprehensive Guide. Edited by Bernd Kortmann and Johan van der Auwera. Berlin/New York: De Gruyter Mouton, pp. 69-96.

Kihm, Alain. 2003. Inflectional categories in creole languages. In Phonology and Morphology in Creole Languages. Edited by Ingo Plag. Tübingen: Niemeyer, pp. 333-63.

Kihm, Alain. 2013. Pidgin-creoles as a scattered sprachbund: Comparing Kriyol and Nubi. In Creole Languages and Linguistic Typology. Edited by Parth Bhatt and Tonjes Veenstra. Amsterdam/Philadelphia: Benjamins, pp. 95-139.

Kiparsky, Paul. 1982. Explanation in Phonology. Berlin/New York: de Gruyter.

Kupisch, Tanja, and Jason Rothman. 2018. Terminology matters! Why difference is not incompleteness and how early child bilinguals are heritage speakers. International Journal of Bilingualism 22: 564-82. [CrossRef]

Lenneberg, Eric. 1967. Biological Foundations of Language. New York: John Wiley \& Sons.

Lindenfelser, Siegwalt, and Péter Maitz. 2017. The creoleness of Unserdeutsch (Rabaul Creole German): A typological perspective. In Language Contact in the German Colonies: Papua New Guinea and beyond. Special issue, Language and Linguistics in Melanesia. pp. 65-90.

Lindenfelser, Siegwalt. Forthcoming. Kreolsprache Unserdeutsch. In Genese und Geschichte einer Kolonialen Kontaktvarietät. Berlin/Boston: de Gruyter.

Maitz, Péter. 2017. Dekreolisierung und Variation in Unserdeutsch. In Räume, Grenzen, Übergänge. Akten des 5. Kongresses der Internationalen Gesellschaft für Dialektologie des Deutschen (IGDD). Edited by Helen Christen, Peter Gilles and Christoph Purschke. Stuttgart: Franz Steiner, pp. 215-42.

Maitz, Péter, and Siegwalt Lindenfelser. 2018. Gesprochenes Alltagsdeutsch im Bismarck-Archipel um 1900. Das Zeugnis regional markierter Superstrateinflüsse in Unserdeutsch. In Variation-Norm(en)-Identität(en). Edited by Alexandra Lenz and Albrecht Plewnia. Berlin/Boston: de Gruyter, pp. 305-337.

McWhorter, John. 2001. The World's simplest grammars are creole grammars. Linguistic Typology 5: 125-66. [CrossRef]

McWhorter, John. 2007. Language Interrupted: Signs of Non-Native Acquisition in Standard Language Grammars. New York: Oxford University Press.

McWhorter, John. 2014. Mesolect as the norm: Semi-creoles revisited. Papia 24: 91-110.

Michaelis, Susanne Maria, Philippe Maurer, Martin Haspelmath, and Magnus Huber, eds. 2013. Atlas of Pidgin and Creole Language Structures Online. Leipzig: Max Planck Institute for Evolutionary Anthropology. Available online: http://www.apics-online.info (accessed on 25 October 2020).

Mosel, Ulrike. 1984. Tolai Syntax and Its Historical Development. Canberra: Australian National University and Research School of Pacific Studies.

Muysken, Pieter. 2016. Creole languages. In Oxford Research Encyclopedias: Linguistics. Oxford: Oxford University Press. Available online: https://oxfordre.com/linguistics/view/10.1093/acrefore/9780199384655.001.0001/ acrefore-9780199384655-e-68 (accessed on 25 October 2020).

O'Neil, Wayne. 1978. The evolution of the Germanic inflectional system: A study of the causes of language change. Orbis 27: 248-86.

Owen, Jonathan. 2013. History. In The Oxford Handbook of Arabic Linguistics. Edited by Jonathan Owen. Oxford/New York: Oxford University Press, pp. 451-71.

Parkvall, Mikael. 2008. The simplicity of creoles in a cross-linguistic perspective. In Language Complexity: Typology, Contact, Change. Edited by Matti Miestamo, Kaius Sinnemäki and Fred Karlsson. Amsterdam/Philadelphia: Benjamins, pp. 265-85.

Petig, William E. 1997. Genitive prepositions used with the dative in spoken German. Die Unterrichtspraxis/Teaching German 30: 36-39. [CrossRef]

Plag, Ingo. 2008. Creoles as interlanguages: Inflectional morphology. Journal of Pidgin and Creole Languages 23: 114-35. [CrossRef] 
Plag, Ingo. 2013. Creolization and admixture. Typology, feature pools, and second language acquisition. In Creole Languages and Linguistic Typology. Edited by Parth Bhatt and Tonjes Veenstra. Amsterdam/Philadelphia: Benjamins, pp. 141-62.

Rickford, John R. 2004. Implicational scales. In The Handbook of Variation and Change. Edited by J. K. Chambers, Peter Trudgill and Natalie Schilling-Estes. Malden: Wiley-Blackwell, pp. 142-67.

Roberts, Sarah J., and Joan Bresnan. 2008. Retained inflectional morphology in pidgins: A typological study. Linguistic Typology 12: 269-302. [CrossRef]

Schmidt, Thomas, Wilfried Schütte, and Jenny Winterscheid. 2015. cGAT. Konventionen für das Computergestützte Transkribieren in Anlehnung an das Gesprächsanalytische Transkriptionssystem 2 (GAT2). Version 1.0. Available online: https://ids-pub.bsz-bw.de/frontdoor/index/index/docId/4616 (accessed on 25 October 2020).

Schmidtkunz, Lena. Forthcoming. The effects of language contact on the aspect system of Unserdeutsch: A contrastive analysis. submitted.

Scott, Alan K. 2011. Everyday language in the spotlight: The decline of the genitive case. German as a Foreign Language 1: 53-70.

Szmrecsanyi, Benedikt, and Bernd Kortmann. 2012. Introduction: Linguistic complexity-Second language acquisition, indigenization, contact. In Language Complexity: Second Language Acquisition, Indigenization, Contact. Edited by Bernd Kortmann and Benedikt Szmrecsanyi. Berlin: de Gruyter, pp. 6-34.

Thomason, Sarah G., and Terrence Kaufman. 1988. Language Contact, Creolization, and Genetic Linguistics. Berkeley: University of California Press.

Trudgill, Peter. 2001. Contact and simplification. Historical Baggage and Directionality in Linguistic Change. Linguistic Typology 5: 371-74.

Trudgill, Peter. 2010. Investigations in Sociohistorical Linguistics. Stories of Colonisation and Contact. Cambridge: Cambridge University Press.

Trudgill, Peter. 2011a. Sociolinguistic Typology: Social Determinants of Linguistic Complexity. Oxford: Oxford University Press.

Trudgill, Peter. 2011b. Social structure, language contact and language change. In The SAGE Handbook of Sociolinguistics. Edited by Ruth Wodak, Barbara Johnstone and Paul Kerswill. Los Angeles: SAGE, pp. 236-48.

Vaissière, Jacqueline. 1996. From Latin to Modern French. On diachronic changes and synchronic variations. In AIPUK: Arbeitsberichte des Instituts für Phonetik und digitale Sprachverarbeitung, Universität Kiel. Universität Kiel: Institut für Phonetik und digitale Sprachverarbeitung, pp. 61-74.

Versteegh, Kees. 1984. Pidginization and Creolization: The Case of Arabic. Amsterdam/Philadelphia: Benjamins.

Volker, Craig A. 1982. An Introduction to Rabaul Creole German (Unserdeutsch). Master's thesis, University of Queensland, Brisbane, Australia.

Volker, Craig A. 1991. The birth and decline of Rabaul Creole German. Language and Linguistics in Melanesia 22: 143-56.

Publisher's Note: MDPI stays neutral with regard to jurisdictional claims in published maps and institutional affiliations.

(C) 2020 by the author. Licensee MDPI, Basel, Switzerland. This article is an open access article distributed under the terms and conditions of the Creative Commons Attribution (CC BY) license (http://creativecommons.org/licenses/by/4.0/). 